Rev Biomed 2005; 16:147-149.

\title{
Florecimiento primaveral de Alexandrium sp. Halim, en aguas costeras de Bahía de Banderas Jalisco-Nayarit, México.
}

Carta al Editor

María del Carmen Cortés-Lara.

Departamento de Ciencias, Centro Universitario de la Costa, Campus Puerto Vallarta. Universidad de Guadalajara, Guadalajara, Jalisco, México.

En los últimos años, las costas de Bahía de Banderas en el Pacífico Mexicano, han estado expuestas a frecuentes florecimientos algales, tanto tóxicos como nocivos, mostrando importantes variaciones interanuales (1). Recientemente nuestros estudios en esta localidad han registrado la ocurrencia de un inusual florecimiento de microalgas asociado a Alexandrium sp. durante la primavera del 2004. Este dinoflagelado marino ha sido señalado en repetidas ocasiones como uno de los principales taxa generadores de mareas rojas en los océanos del mundo, productor de toxinas del grupo PSP (Paralytic Shellfish Poisoning).

Durante el florecimiento de esta especie, se presentó una intensa coloración del agua de mar, por lo que varias estaciones de muestreo de Bahía de Banderas fueron monitoreadas casi diariamente, para determinar la abundancia de fitoplancton tóxico, entre las diferentes estaciones de muestreo. El estudio consistió en la colecta de muestras de agua con la ayuda de una botella Van-Dorn de un litro de capacidad en superficie y dos metros de profundidad. Simultáneamente se determinó la temperatura utilizando un termómetro de cubeta de $0.1^{\circ} \mathrm{C}$ de precisión y la salinidad con un refractómetro ATAGO S/Mill-E de $0-100 \%$ al $1 \%$ de precisión. Las muestras se preservaron con una solución de acetato Lugol en una proporción de 1:100 (2), y cuantificadas por el método del microscopio invertido (3) en cámaras Sedgewick Rafter con capacidad $1 \mathrm{ml}$ marcadas en recuadros de $1 \mathrm{~mm}^{2}$ como marco de referencia.

Los resultados de las muestras de fitoplancton indicaron que las concentraciones de este dinoflagelado tóxico aumentaron gradualmente durante el mes de marzo, alcanzando abundancias máximas de 3'176,000 Cel.L -1 $^{-1}$, siendo escasa la concentración de otras especies fitoplanctónicas. Esta densa floración algal se observó en el ambiente natural cubriendo grandes extensiones al norte de la bahía, a manera de parches con una duración de al menos 10 días. Se observaron además células independientes del género Alexandrium, muy pequeñas en talla variando de 25-28 $\mu$ de ancho por 23-27 $\mu$ de largo. Junto con la decoloración del mar se reportaron mortandad de peces; desafortunadamente los organismos fueron removidos por lo que no hubo forma de poder

Solicitud de sobretiros: María del Carmen Cortés-Lara. Departamento de Ciencias, Centro Universitario de la Costa, Campus Puerto Vallarta. Universidad de Guadalajara, Guadalajara, Jalisco, México.

E-mail: carmen_corteslara@yahoo.com.mx.

Recibido el 4/Enero/2005. Aceptado para publicación el 7/Enero/2005.

Este artículo está disponible en http://www.uady.mx/sitios/biomedic/revbiomed/pdf/rb051628.pdf

Vol.16/No.2/Abril-Junio, 2005 


\section{M del C Cortés-Lara.}

identificarlos ni cuantificarlos.

En la fig. 1 se muestra una microfotografía de Alexandrium sp., como organismo dominante de la marea roja de la Bahía de Banderas, tomada en un fotomicroscopio compuesto Olympus $\mathrm{CH} 30$ con objetivos 40X en el Departamento de Ciencias.

Es importante resaltar que este nuevo florecimiento fitoplanctónico en la bahía forma parte de los resultados del Programa de Monitoreo de Mareas Rojas del Centro Universitario de la Costa, campus Puerto Vallarta (Universidad de Guadalajara) en el 2004, el cual mantiene acciones sistemáticas de monitoreo desde el 2000 en esta franja litoral del estado de Jalisco.

Basados en los registros históricos de florecimientos algales o mareas rojas en Bahía de Banderas, es la primera vez que se documenta la abundancia y distribución de Alexandrium sp. en esta zona geográfica. Aunque es un taxón común, la relevancia de este tipo de registros sugiere que la presencia de Alexandrium sp. podría ser prevalerte en estas costas, además de un importante factor de mortandad de peces, intoxicación en humanos y de mortandad de otros grupos marinos como mamíferos $\mathrm{y}$ aves $(4,5)$. Esto se ha manifestado debido a que las especies de Alexandrium producen potentes neurotoxinas del grupo PSP las cuales son transferidas a los moluscos bivalvos durante los procesos normales de alimentación. Así, es importante entender que los humanos al consumir mariscos contaminados, estarían expuestos a serios problemas de salud cuando las toxinas PSP están presentes (5).

De hecho, los especialistas en la materia sostienen que el nivel de toxicidad en los moluscos podría manifestarse aún cuando las densidades celulares de Alexandrium sp están por debajo de las 100-200 células por litro (6). Finalmente, una pregunta fundamental a contestar es saber si la proliferación de Alexandrium sp. en la bahía resulta de un crecimiento in situ, o si por el contrario se trata de poblaciones alóctonas concentradas y redistribuidas en la zona por procesos físicos costeros incluyendo tormentas tropicales y huracanes.

Palabras clave: Dinoflagelados tóxicos, Alexandrium sp., Bahía de Banderas Jalisco Nayarit, florecimientos algales.

\section{AGRADECIMIIENTOS.}

Se agradece el apoyo económico del Centro Universitario de la Costa (U de G) y la valiosa colaboración del M.C. Roberto Cortés Altamirano en el trabajo de laboratorio. De igual forma, se agradece a los miembros de la XII Zona Naval Militar de Puerto Vallarta, Armada de México por su asistencia en las salidas de campo permitiéndonos utilizar sus embarcaciones, en especial al Tnte. de Corbeta Químico Luís Vidal Rodríguez Nava.
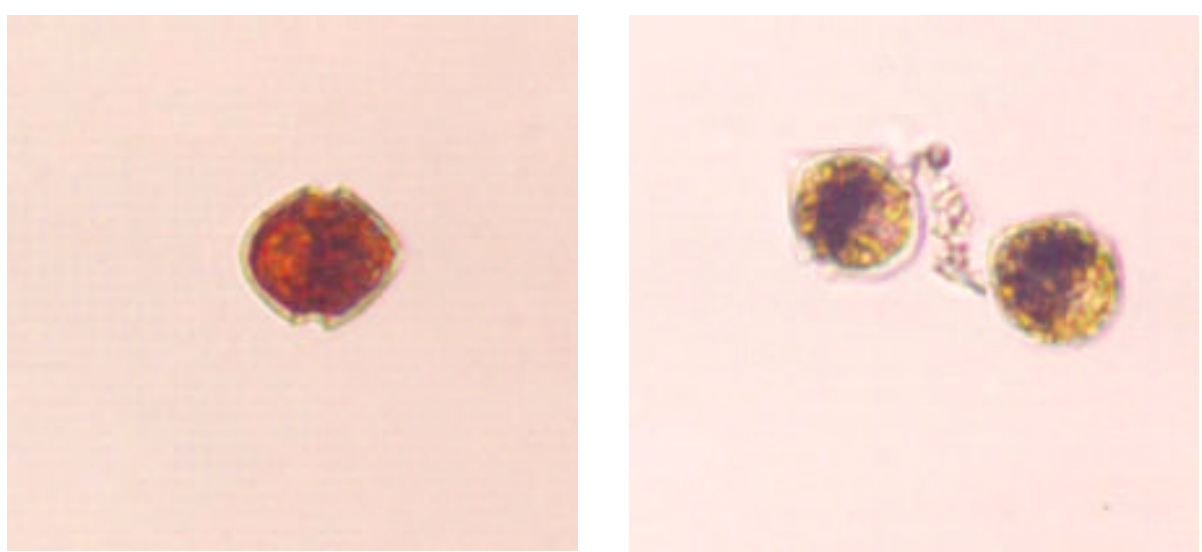

Figura 1.- Vista ventral de Alexandrium sp., tomada en un fotomicroscopio de luz.

\section{Revista Biomédica}




\section{Florecimiento de Alexandrium sp. Halim en Bahía de Banderas, México.}

\section{REFERENCIAS.}

1.- Cortés-Lara MC, Cortés-Altamirano R, Sierra-Beltrán AP. Participación del Centro Universitario de la Costa, campus Puerto Vallarta, en las actividades del Plan Nacional de Monitoreo de Mareas Rojas. Memorias de la XIII Reunión Nacional de la Sociedad Mexicana de Planctología A.C. VI Reunión Internacional de Planctología, Nuevo Vallarta, Nayarit; 2004. p. 57.

2.- Cortés-Altamirano R, Hernández-Becerril DU. Especies responsables y probables de mareas rojas en México. En: Mareas Rojas. Cortés-Altamirano R, México: AGT Editor; 1998. p. 43-79.

3.- Hasle GR. Using the inverted microscope. In: Sournia A., editor. Phytoplankton Manual. Paris: UNESCO; 1978. p. 1916.

4.- Ogata T, Kodama M. Ichthyotoxicity found in cultured media of Protogonyaulax spp. Mar Biol 1986; 92:31-4.

5.- Anderson DM. The growing problem of harmful algae. Tiny plants pose a potent threat to those who live in and eat from the sea. Oceanus 2004; 43:1-5.

6.- Anderson DM. Bloom dynamics of toxic Alexandrium species in the northeast U.S. Limnology and Oceanography 1997; 42:1009-22. 